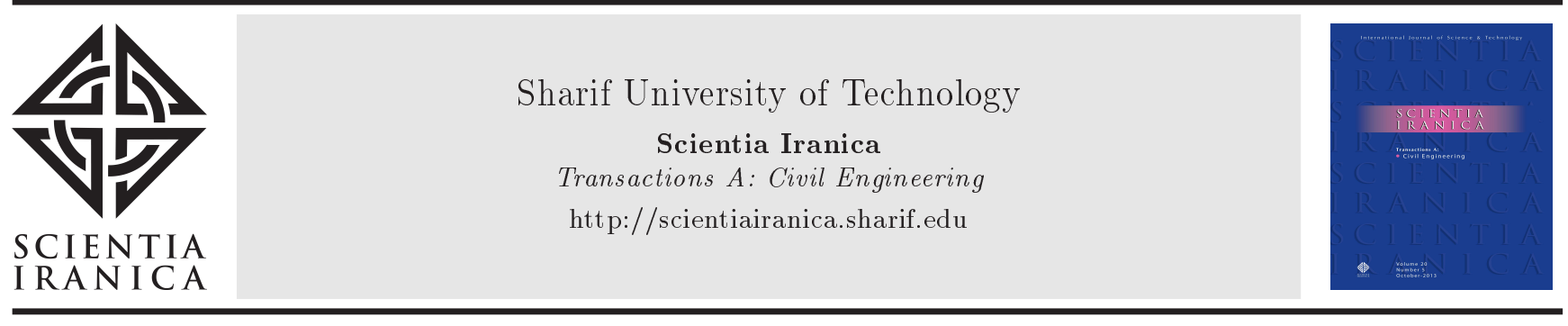

\title{
Flexural retrofitting of the damaged reinforced concrete beams by using HPFRCC
}

\author{
M.K. Sharbatdar* and J. Ayyubi \\ Faculty of Civil Engineering, Semnan University, Semnan, Iran. \\ Received 23 January 2017; received in revised form 19 November 2018; accepted 10 February 2020
}

\section{KEYWORDS}

HPFRCC;

Damaged;

Retrofitting;

Steel fibres;

Ductility;

Flexural capacity;

Numerical.

\begin{abstract}
Damaged structures are not usually reliable to tolerate designed loads and therefore, it is required to retrofit structural parts. The main purpose of this paper is to utilize High-Performance Fibre-Reinforced Cement-based Composite (HPFRCC) as a high-performance material to recover the damaged beams and improve their ductility and moment capacity with experimental approaches. In addition, a retrofitting method was presented using HPFRCC. The experimental study was performed on three simply supported beams with the same dimension, materials, and reinforcement configuration. The first beam, known as the reference beam, is subjected to the pure bending condition until its failure and the others are prone to a certain amount of load according to the final capacity of the first beam. Thereafter, two damaged beams are retrofitted using HPFRCC in the created grooves on the tensile surface of the beam; finally, these retrofitted beams are loaded to determine the bending behavior. Experimental results demonstrate that retrofitting can improve the first crack strength, load in yield condition, and maximum load capacity. Also, the proposed method increases the ductility and energy absorption of retrofitted beams.
\end{abstract}

(C) 2020 Sharif University of Technology. All rights reserved.

\section{Introduction}

Concrete is the most used constructive material all over the world [1]. Compared with other constructive materials, it has a lower cost/strength ratio (Altun et al. (2007) [2]. Reinforced Concrete (RC) structures often require repairing and/or strengthening due to a change of use, design with old normative, change of design philosophy as the case of capacity design of $\mathrm{RC}$, aging or deterioration of materials produced by environment factors, construction faults, or material damage due to extreme loading [3]. The reduction of governmental funds for new constructions has also led

\footnotetext{
*. Corresponding author.

E-mail address: msharbatdar@semnan.ac.ir (M.K. Sharbatdar)
}

to the new tendency of increasing service life of existing structures [4]. Structures and their components need to be retrofitted for different reasons. General reasons that make the retrofitting necessary are design error, change in application, incorrect implementation, and damage during the usage of the structure or earthquake. In typical structural systems such as moment frames and dual systems, beams are very important in the seismic capacity of the whole system. These elements need high ductility and appropriate strength and intensity related to ductility to behave reasonably in structure. For this purpose, designers should diagnose the dominant behavior of beams in structure before initiating the process of retrofitting and then, select the appropriate method to initiate the aforementioned process. In recent years, many researches have been conducted on the bending and shear retrofitting of RC beams with different materials such as steel plates, Fiber-Reinforced Polymer 
(FRP) plates, Near Surface Mounted (NSM) methods, and High-Performance Fibre-Reinforced Cement-based Composite (HPFRCC) material [5-7]. For instance, laboratory investigations of RC beams were performed with novel technology of HPFRCC concrete [8] and bending retrofitting RC beams with HPFRCC and Carbon Fiber Reinforced Polymer (CFRP) by Ferrari et al. [5]. In all of the pre-mentioned studies, using the HPFRCC concrete enhances the bending performance of the beams and frames [9-12]. In addition, the method of strengthening should provide appropriate reliability, efficiency, and affordability. Strengthening structural elements can be carried out by adding some technology, accessory, component, or feature to it. Considering the previous studies and the importance of retrofitting structural elements, scrutinizing the bending behavior of the damaged beams retrofitted with HPFRCC has been considered in this research. Using high-performance materials instead of common materials has long been of interest of researchers which performed many studies on them. As known earlier, using the novel materials and special composites in the last decade was extremely interesting. The first effort for concrete retrofitting was done by placing steel fibers [13,14]. The structural behavior of RC beams strengthened with FRP was studied by several researchers. Sheikh et al. [15] studied damaged specimens that were repaired with FRP sheets and wraps and were tested to failure. Companion control specimens were also tested to failure without rehabilitation to provide a basis for comparison and evaluation of the effectiveness of repair techniques. Test results showed that FRPs were effective in strengthening for flexure as well as shear. Flexural over-reinforcement resulted in shifting the failure to shear mode, which may be undesirable in some cases. Strengthening of a structural element in shear, on the other hand, resulted in increasing the ultimate displacement by more than tenfold and toughness by a factor of more than 26 , and many researchers are paying attention to FRPs because of their significant advantages to attain high strain rates. However, the actual FRP products are skill-dependent and the quality may not be uniform. Apart from the economic point of view and the cost, the most essential problem in the FRP system is the "bond" between the FRP and concrete. The ACI 440 assumes only two failure modes for design calculations:

1. Compressive failure of the concrete;

2. Failure of the FRP strengthening system.

Typical failure modes of FRP-plates or sheet reinforced RC beams are classified as FRP rupture, crushing of compressive concrete, shear failure, concrete cover separation and plate-end interfacial de-bonding, intermediate flexural crack-induced interfacial de-bonding, and intermediate flexural shear crack-induced interfacial de-bonding. Also, almost all failure modes show a brittle manner. $\mathrm{Li}$ and $\mathrm{Wu}$ [16] introduced a pseudo-strain hardening material that used only fine aggregates with polyethylene-reinforced fibers. Later, Naaman and Reinhardt [17] proposed a characterization framework for any materials developed over the preceding years. High tensile ductility and strain hardening behaviors are the most important characteristics of this material, which is called HPFRCC. In recent years, a new class of HPFRCC has emerged, entitled Engineered Cementitious Composite (ECC) [18]. It was originally developed at the University of Michigan with a typical tensile strength of $4-6 \mathrm{MPa}$ and ductility of $3-$ $5 \%$ [19]. The tensile and compressive envelope curves of concrete and HPFRCC and then the analytical models calibrated with experimental works [20] were added to the software. Nowadays, a new generation of Fiber-Reinforced Cement-based Composites (FRCCs) demonstrating strain hardening behavior along with a remarkable tensile strain capacity as well as providing multiple fine cracks under the uni-axial load condition is High-Performance Fiber Reinforced Cementitious Composite, called HPFRCC. It is of interest to note that the proposed composite material could maintain load-carrying capacity after first cracking. Load can be transferred by fiber bridging from this crack plane back into brittle matrix, leading to the formation of another crack, which may originate from a different matrix defect region. Through the repetition of this process, multiple cracking develops with an intrinsically controlled crack width limit in the order of $200 \times 10^{-3}$ during tensile loading.

Flexural capacity of RC beams can be increased by using externally bonded HPFRCCs. In this regard, the researchers used a HPFRCC Laminates technique for strengthening [21]. Bending behavior of HPFRCC influenced by its tensile ductility was performed by many studies [22-24]. Multiple micro-cracks were formed at the end of beam due to bending, which let the curvature of the beam develop. The most important advantage of composite materials [25] is high strength and ductility, which allow them to be used for retrofitting damaged or weak structures and to enjoy more application in concrete structures than steel ones [11]. In this respect, according to the present research, a technique for the flexural strengthening of damaged $\mathrm{RC}$ beams is proposed. This research focuses on the basis of a HPFRCC for constructing a more effective transition layer.

\section{Experimental plan}

\subsection{Materials properties}

In this proposed plan, three hinged supported beams with the same dimensions, materials, and reinforce- 

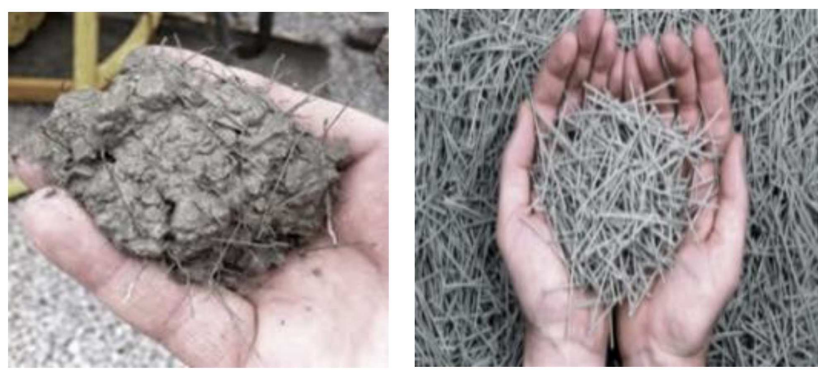

Figure 1. Steel fibers, individual, and mixed with concrete.

ments were tested. The typical and HPFRCC concrete mix compositions are given in Table 1 . No coarse aggregate was used for HPFRCC mix design and a special super plasticizer should be used to acquire some particular properties of this material. The 28-day compressive strength of typical concrete and HPFRCC samples was 35.5 and $65.2 \mathrm{MPa}$, respectively, as shown in Table 2. The yield stress values of tensile (at the bottom of the beam) and compressive (at top of the beam) steel reinforcement bars were equal to 338 and $379.9 \mathrm{MPa}$, respectively. Figure 1 depicts the type of steel fibres used in this study and thus, their properties are given in Table 3 . Since the steel fibres have unique specifications in comparison to other fibres in increasing capacity and stiffness, they have been used for making HPFRCC and retrofitting concrete beams.

Table 1. Concrete mix compositions.

\begin{tabular}{ccc}
\hline \multirow{2}{*}{ Materials } & \multicolumn{2}{c}{ Mix proportions $\left(\mathrm{kg} / \mathbf{m}^{3}\right)$} \\
\cline { 2 - 3 } & $\begin{array}{c}\text { HPFRCC } \\
\text { concrete }\end{array}$ & $\begin{array}{c}\text { Normal } \\
\text { concrete }\end{array}$ \\
\hline Water & 2.1 & 52.5 \\
Cement & 4.1 & 66 \\
Sand & 325 & 186 \\
Sand $<2.36 \mathrm{~mm}$ & 812 & 429 \\
Gravel & - & 662 \\
\hline
\end{tabular}

Table 2. Compressive strength for concrete samples.

\begin{tabular}{ccc}
\hline & \multicolumn{2}{c}{$\begin{array}{c}\text { Compressive strength } \\
\text { Sample no. }\end{array}$} \\
\cline { 2 - 3 } & $\begin{array}{c}\text { Normal } \\
\text { concrete }\end{array}$ & $\begin{array}{c}\text { HPFRCC } \\
\text { concrete }\end{array}$ \\
\hline 1 & 66.5 & 32.8 \\
2 & 70.2 & 30.2 \\
3 & 63.3 & 37.8 \\
4 & 60.8 & 35 \\
5 & - & 34.7 \\
6 & - & 36.9 \\
Average & 65.2 & 35.5 \\
\hline
\end{tabular}

Table 3. Properties of steel fibres.

\begin{tabular}{cccc}
\hline $\begin{array}{c}\text { Length } \\
(\mathbf{m m})\end{array}$ & $\begin{array}{c}\text { Diameter } \\
(\mathbf{m m})\end{array}$ & $\begin{array}{c}\text { Length } \\
\text { diameter ratio }\end{array}$ & $\begin{array}{c}\text { Density } \\
\left(\mathbf{k g} / \mathbf{m}^{\mathbf{3}}\right)\end{array}$ \\
\hline 36 & 0.8 & 45 & 7850 \\
\hline
\end{tabular}

Accordingly, these steel fibres have been mixed with the concrete with $2 \%$ of volume ratio of concrete

\subsection{Beams characteristics}

In this research, an experimental test was performed on three hinged supported beams with the same dimensions, materials, and reinforcement with flexural dominated behavior. Note that providing enough stirrups would prevent shear failure in beams. The first beams called RC and known as reference beam was subjected to pure bending until its ultimate load capacity $\left(P_{u}\right)$ and failure mode, and the others were subjected to certain amounts of load equal to $35 \%$ and $75 \%$, according to the ultimate capacity of the first beam. The main reason why we opted the $35 \%$ ultimate load of the reference specimen is that under this load, the behavior of beam lies between the elastic point and yielding point and has not been prone to severe loads and also, $75 \%$ ultimate load is the beam behavior that lies between the yielding point and ultimate capacity and has been subjected to severe loads. Damaged beams were retrofitted by forming a layer of HPFRCC by shuttering and concreting in molds at the bottom parts of both damaged beams in U-shape. As shown in Table 4, letter B refers to Beam and the next two digits show the percentage of damage (for example, 35\%) and the next one indicates the retrofitting material, which is HPFRCC. In order to analyze the bending behavior of beams, selected samples should have the same dimension as real ones in structures to gain reliable results. To investigate the bending behavior, the four-point loading pattern was selected to provide a pure bending portion in beams. Supports were considered as hinged to easily perform the experiment. Given the lab limitations, the length of the beam was $2300 \mathrm{~mm}$ and according to supports at two ends, the center-to-center distance of $2100 \mathrm{~mm}$ was provided. The free length of the beam was divided into 3 parts and two-point loads with a distance of $700 \mathrm{~mm}$ from

Table 4. Beams characteristics.

\begin{tabular}{cc}
\hline Beam & \multicolumn{1}{c}{ Characteristics } \\
\hline RC & RC beam, without strengthening \\
RC beam, damaged up to $35 \%$ \\
B35H & $\begin{array}{l}\text { ultimate load of RC and then, } \\
\text { retrofitted by HPFRCC layer }\end{array}$ \\
& $\begin{array}{l}\text { RC beam, damaged up to } 75 \% \\
\text { ultimate load of RC and then, } \\
\text { retrofitted by HPFRCC layer }\end{array}$ \\
\hline
\end{tabular}


each other placed on the beam symmetrically. Stirrups in beams were provided such that shear cracks would not govern the crack patterns of the beam and all the destruction caused by bending. Dimensions of beam's cross-section were $200 \mathrm{~mm}$ width and $250 \mathrm{~mm}$ height, as shown in Figure 2, in which all beams had three tensile steel bars with a $12 \mathrm{~mm}$ diameter at the bottom and two compressive steel bars with a $10 \mathrm{~mm}$ diameter at the top of the beam and $8 \mathrm{~mm}$ stirrups placed every $15 \mathrm{~cm}$.

\subsection{Test setup}

Considering that beams are simply supported at a distance of $2100 \mathrm{~mm}$ from each other, as demonstrated in Figure 3. Two strain gauges were installed at midspan on the upper bars and two strain gauges on the lower bars so that the total of four strain gauges could be used to investigate the behavior of these beams.

\subsection{Retrofitting of damaged beams}

The first beam (reference beam) was subjected to severe load to measure the final crack and two other damaged beams were subjected to 35 and $75 \%$ ultimate loads $\left(P_{u}\right)$ of the reference beam. In order to ensure the unity and combination treatment of HPFRCC layer and existing concrete in beam and prevent any possible de-bonding of HPFRCC layer from the concrete hard surface, some grooves, as shown in Figure 4, with $30 \mathrm{~mm}$ in depth and $40 \mathrm{~mm}$ in width were provided using the electrical Grinder machine. Two damaged beams, as shown in Figure 5, were retrofitted, forming a layer of HPFRCC as well as shuttering and concreting

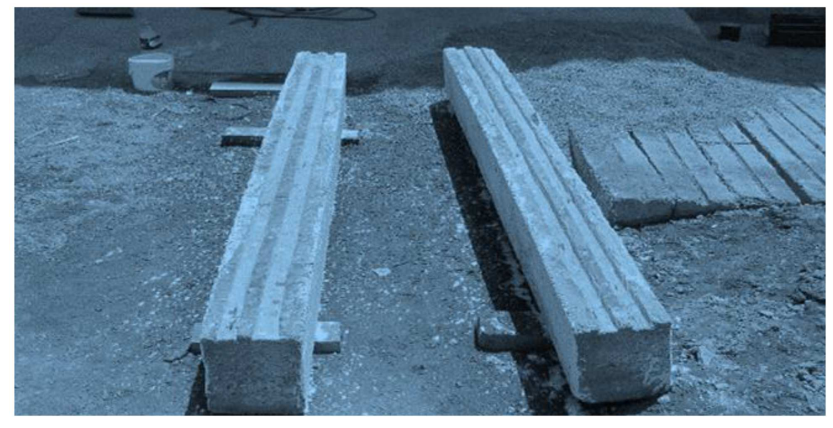

Figure 4. Creation grooves on the tensile surface.

in molds at the bottom parts of the beam in U-shape. It is worth noting that the thickness of HPFRCC layer in all samples is equal to $20 \mathrm{~mm}$ (the minimum practical thickness).

\section{Results and discussions}

\subsection{Observations and load-deflection response}

The RC beam with a rectangular cross-section was considered as the reference beam whose reinforcement was quite similar to other samples. This hinged support beam was subjected to the 4-point loading pattern. Before starting the test, the required equipment such as strain gauges, Linear Variable Displacement Transducers (LVDTs), and load-cell was installed on the sample to measure strains on bars, mid-span deflection, and applied loads. The first cracks in the sample occurred due to bending under a force of about $40 \mathrm{kN}$ at midspan, and tensile reinforcement yielding happened at $65.8 \mathrm{kN}$ from strain gauge reading attached to steel

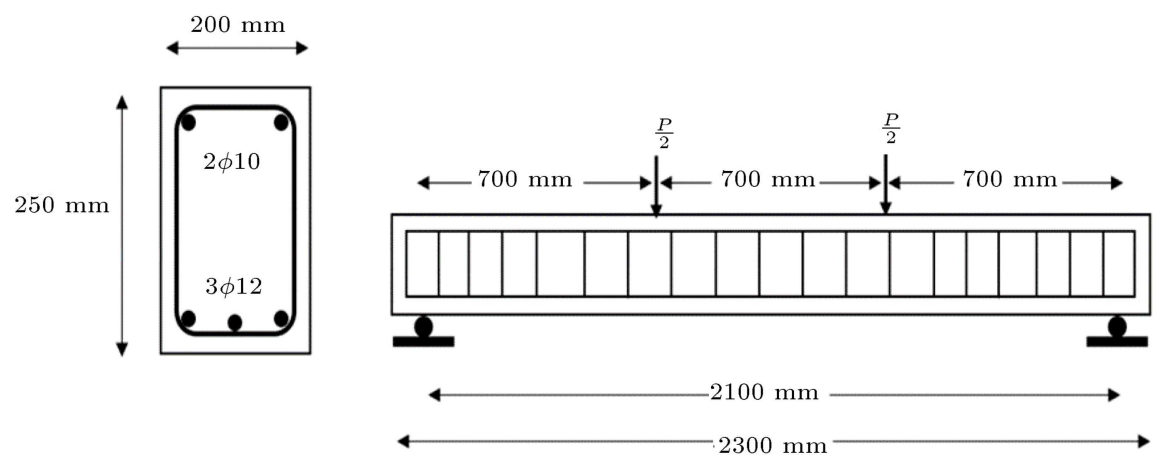

Figure 2. The details of reinforced concrete specimens.
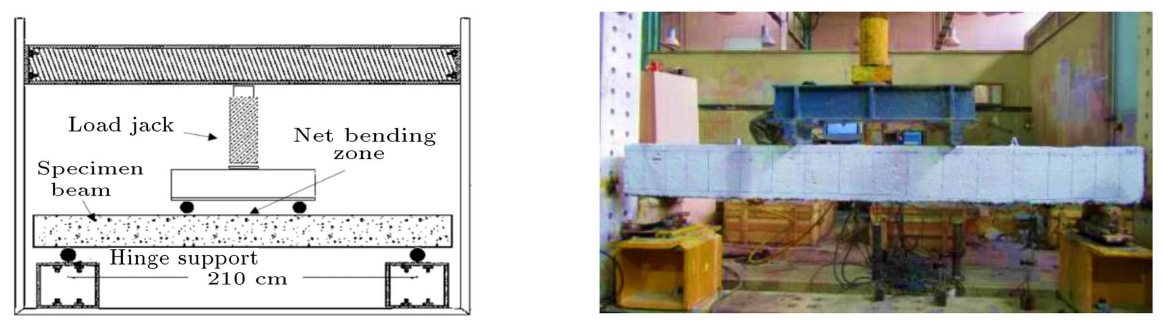

Figure 3. General setup of the three-point bending test of specimens. 


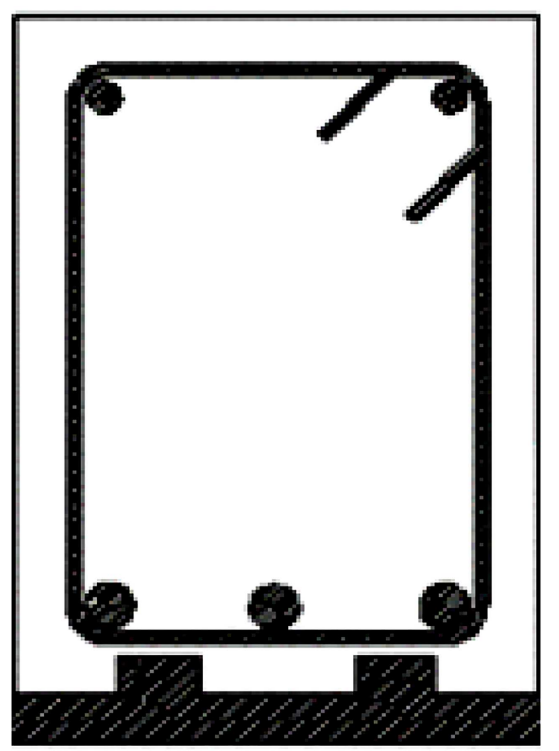

Figure 5. Schematic of the High-Performance Fibre-Reinforced Cement-based Composite (HPFRCC) retrofitting layer.

bars. Also, the cracks began to appear with tensile cracks at the mid-span and gradually expanded to the supports and thereafter, their width increased. Shear cracks in the vicinity of supports appeared at a 45-degree angle so that the more the applied force increased, the more they expanded and moved to the compression region of beam. By increasing the amount of applied force, the compressive force region in the upper part of the beam was destroyed. Followed by failure, beams' bearing reduction, and displacements in the mid-span, the test was finished. Finally, as shown in Figure 6, the beam was crushed; the RC in accordance with the load-deflection curve in Figure 7 resulted in the force of $88.33 \mathrm{kN}$ and a maximum displacement of $42 \mathrm{~mm}$. In order to have the damaged beams as those shown in Figure 8, after loading the reference sample and reaching the maximum loading equal to $88.33 \mathrm{kN}$, two other beams were initially

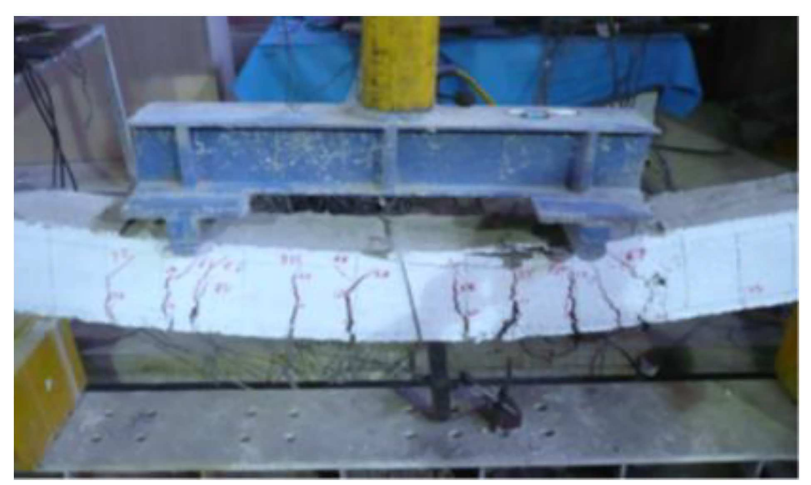

Figure 6. Reinforced Concrete (RC) beam failure at the end of test.

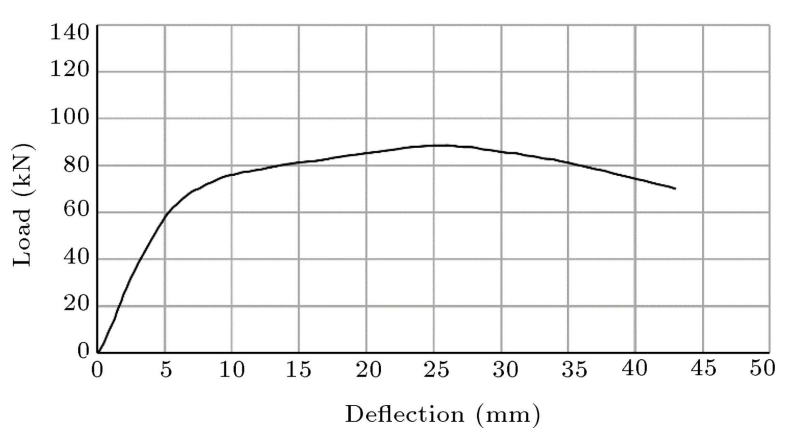

Figure 7. Load-deflection curve of the RC beam.

loaded up to 35 and $75 \%$ of final load equal to 30.9 and $66.2 \mathrm{kN}$, respectively.

Then, both damaged beams were retrofitted with HPFRCC of two-centimeter layers and prepared for new loading up to those ultimate capacities. In the damaged beam retrofitted by HPFRCC with $35 \%$ load called $\mathrm{B} 35 \mathrm{H}$, besides previous cracks existing in the damaged beam, the first cracks in the retrofitted specimen occurred at the mid-span. Tensile steel bars were yielded in a force of about $95 \mathrm{kN}$. Cracks began with tensile cracks occurring at the mid-span and gradually became wider. Shear cracks appeared close to the supports at a 45-degree angle; however, these were limited and increase in their width was negligible. Shear cracks were along both tensile and compressive regions and concrete in the compression region between the two concentrated loads was crushed, as depicted in Figure 9. Finally, according to the load-deflection curve in Figure 10, B35H beam had $135.18 \mathrm{kN}$ force and a displacement up to $43.7 \mathrm{~mm}$. Bridging fibers in the tension cracks in the experiment is also of noteworthy observations. No de-bonding occurred between the beam concrete surface and the HPFRCC layer, even at the end of testing, indicating that groove was effective in preventing possible de-bonding.

In the beam damaged up to $75 \%$ and retrofitted with HPFRCC called $\mathrm{B} 75 \mathrm{H}$, in addition to the previous cracks, the first new cracks occurred at the mid-span under the force of about $66 \mathrm{kN}$. Tensile reinforcement was yielded at $96.5 \mathrm{kN}$. Cracking with tension cracks at the mid-span gradually expanded and increased in width. Shear cracks occurred near the supports with an angle of 45 degrees; however, these cracks were limited, did not increase in width, spread with increasing force, and expanded into the compression region of beam. In this state, there were more bending cracks and their widths also increased. Shear cracks were across both tensile and compressive regions of concrete and the concrete in the compressive region was crushed between the two centralized forces, as shown in Figure 11. Finally, the $\mathrm{B} 75 \mathrm{H}$ beam, according to the load-deflection curve in Figure 12, resulted in a force about $113.1 \mathrm{kN}$ and the maximum displacement of $46 \mathrm{~mm}$. Bridging fibers in the tension cracks is an 


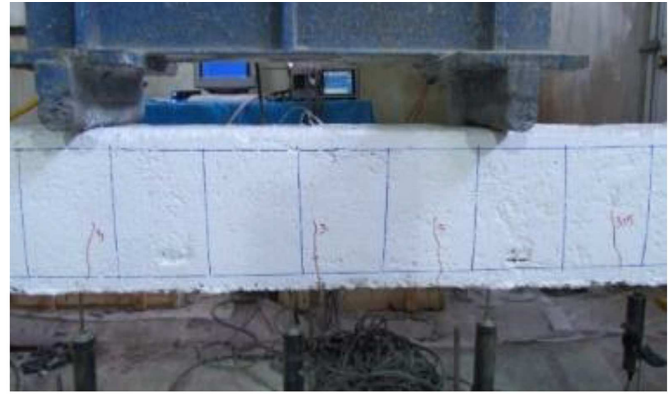

(a) $35 \%$ damaged beam

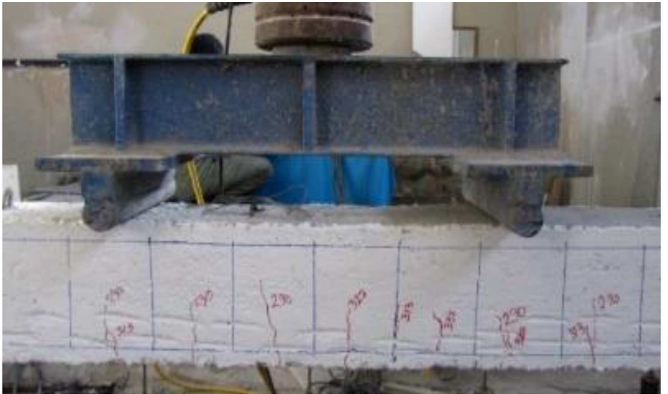

(b) $75 \%$ damaged beam

Figure 8. Damaged beams before retrofitting.

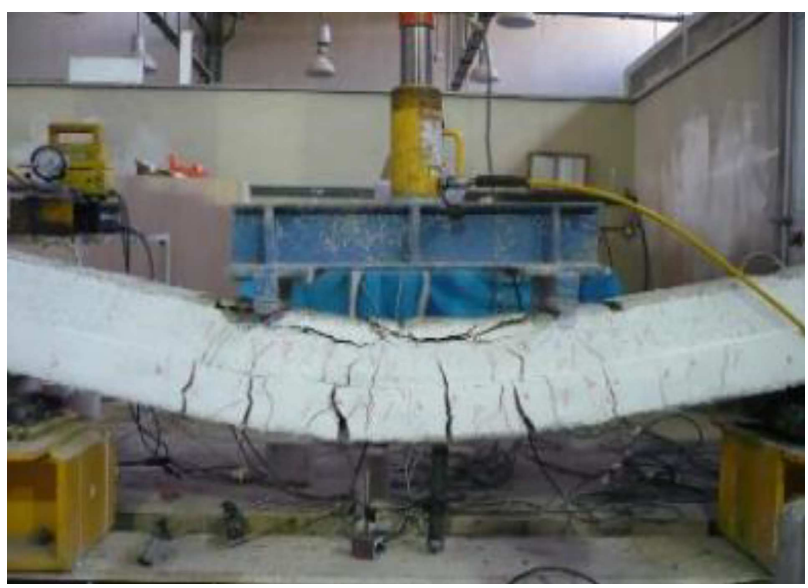

Figure 9. Retrofitted beam, B35H, at the end of test.



Figure 10. Load-deflection curve of the B35H beam.



Figure 11. Retrofitted beam $\mathrm{B} 75 \mathrm{H}$ at the end of test. interesting observation in this experiment, too. No de-bonding observed between beam concrete surface and HPFRCC layer even at the end of testing $\mathrm{B} 75 \mathrm{H}$ specimen such as the $\mathrm{B} 35 \mathrm{H}$ specimen, indicating that grooves were effective to prevent possible de-bonding at both strengthened specimens. As shown in Figure 12, the load-displacement curve has the strain hardening of HPFRCC layer after steel bar yielding and prior to reaching the maximum capacity of the beam.

\subsection{Comparison of capacities}

Values of cracking, yielding, and ultimate loads $\left(P_{c r}\right.$, $\left.P_{y}, P_{u}\right)$ as well as the corresponding displacements $\left(\Delta_{c r}, \Delta_{y}, \Delta_{u}\right)$ of three specimens are given in Table 5 , with the load-deflection curves shown in Figure 13.

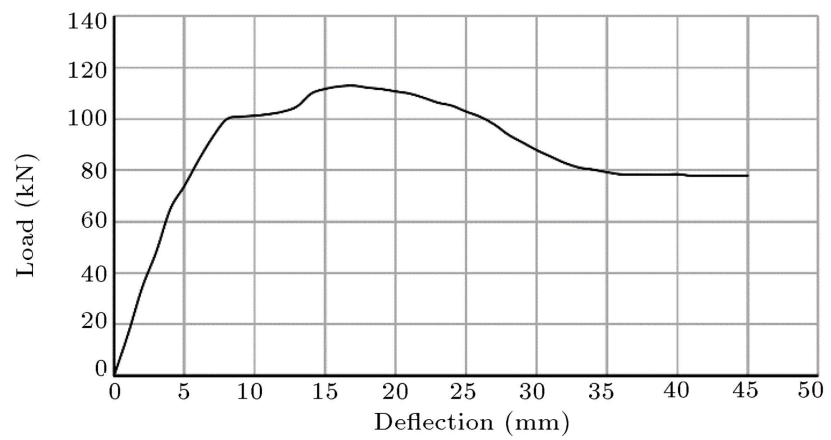

Figure 12. Load-deflection curve of the B75H beam.

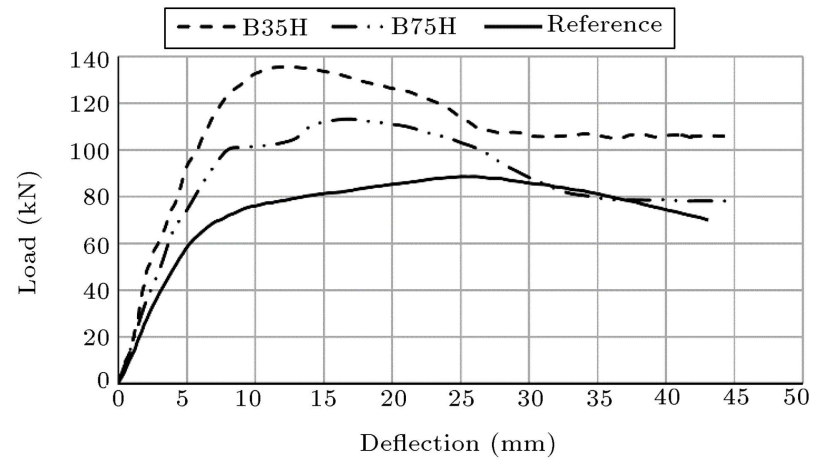

Figure 13. Load-deflection curves of the beams Reinforced Concrete (RC), B35H, and B75H. 
Table 5. Loads and deflections of beams.

\begin{tabular}{ccccccc}
\hline Beam & $\boldsymbol{\Delta}_{\boldsymbol{c r}}(\mathbf{m m})$ & $\boldsymbol{P}_{\boldsymbol{c} \boldsymbol{r}}(\mathbf{k N})$ & $\boldsymbol{\Delta}_{\boldsymbol{y}}(\mathbf{m m})$ & $\boldsymbol{P}_{\boldsymbol{y}}(\mathbf{k N})$ & $\boldsymbol{\Delta}_{\boldsymbol{u}}(\mathbf{m m})$ & $\boldsymbol{P}_{\boldsymbol{u}}(\mathbf{k N})$ \\
\hline $\mathrm{RC}$ & 3.6 & 45 & 6.2 & 65.8 & 42 & 88.33 \\
$\mathrm{~B} 35 \mathrm{H}$ & 2.1 & 52.5 & 5.1 & 95 & 43.7 & 135.18 \\
$\mathrm{~B} 75 \mathrm{H}$ & 4.1 & 66 & 6.5 & 96.5 & 46 & 113.10 \\
\hline
\end{tabular}

Table 6. Loads, failure modes, and comparative of beams load.

\begin{tabular}{|c|c|c|c|c|c|c|c|c|}
\hline Beam & $\frac{P_{u}}{P_{y}}$ & $\frac{P_{u}}{P_{u}(R C)}$ & $\frac{P_{y}}{P_{y}(R C)}$ & $\frac{P_{c r}}{P_{c r}(R C)}$ & $\begin{array}{c}M_{u \exp } \\
(\mathrm{kN} . \mathrm{m})\end{array}$ & $\begin{array}{c}P_{u} \\
(k N)\end{array}$ & $\begin{array}{c}P_{y} \\
(\mathbf{k N})\end{array}$ & $\begin{array}{c}P_{c r} \\
(\mathrm{kN})\end{array}$ \\
\hline $\mathrm{RC}$ & 1.34 & 1.00 & 1.00 & 1.00 & 30.9 & 88.33 & 65.8 & 45 \\
\hline B35H & 1.42 & 1.53 & 1.44 & 1.167 & 47.69 & 135.18 & 95 & 52.5 \\
\hline $\mathrm{B} 75 \mathrm{H}$ & 1.17 & 1.28 & 1.47 & 1.467 & 39.55 & 113.1 & 96.5 & 66 \\
\hline $\begin{array}{l}\text { Difference between two } \\
\text { retrofitted beams }\end{array}$ & $\begin{array}{l}-17.6 \% \\
\text { decrease }\end{array}$ & $\begin{array}{l}-16.3 \% \\
\text { decrease }\end{array}$ & $\begin{array}{c}+2 \% \\
\text { increase }\end{array}$ & $\begin{array}{c}+25 \% \\
\text { increase }\end{array}$ & 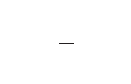 & $\begin{array}{l}-16.3 \% \\
\text { decrease }\end{array}$ & $\begin{array}{c}+1.6 \% \\
\text { increase }\end{array}$ & $\begin{array}{l}+25.7 \% \\
\text { increase }\end{array}$ \\
\hline
\end{tabular}

Comparison of the tested beams and the reference beam is given in Table 6 . It is obvious that retrofitting with HPFRCC generally leads to an increase in all introduced forces of the beams. In retrofitting using HPFRCC, the beam with lower damage percentage (i.e., $35 \%$ ) showed better performance and increased by 53 percent in the ultimate strength; in comparison to the sample with $75 \%$ damage, $28 \%$, and $47 \%$ increases in strength and yield strength were observed. The higher the percentage of damage was, the sooner the beam reached its peak point. In other words, the distance between load yielding point and the maximum load in this beam was shorter, because more damages cause it to be softer and it will bear lower loads. As shown in Figure 13, the slope of the curve of the retrofitted beam is higher than that of the reference beam and the reason is the increase in the intensity of the retrofitted sample in comparison to the reference sample.

\subsection{Ductility of beams}

Ductility is an essential property of structures because it guarantees safety of structures when subjected to accidental, blast, or seismic loads. Displacement ductility $\left(\mu_{\Delta}\right)$ of a structural frame is obtained from the real force-displacement diagram. The ductility factor, $\mu$, is obtained as the ratio between the ultimate displacement $\left(\Delta_{u}\right)$ and the yielding displacement $\left(\Delta_{y}\right)$; $\mu_{\Delta}=\Delta_{u} / \Delta_{y}$. If the amount of loss is more than 20 percent of final load, the value of $\Delta_{u}$ in related load is considered as $0.80 P_{u}$. According to the literature, researchers suggest 30\% loss (displacement corresponding to $70 \%$ of maximum load) for flexible concrete members such as ECC or HPFRCC concrete with higher final compressive strain. Ductility ratios of all three specimens were calculated based on considered $\Delta_{u}$ at $0.80 P_{u}$. Therefore, it is not required to
Table 7. Ductility of beams.

\begin{tabular}{ccccc}
\hline Beam & $\boldsymbol{\Delta}_{\boldsymbol{y}}(\mathbf{m m})$ & $\boldsymbol{\Delta}_{\boldsymbol{u}}(\mathbf{m m})$ & $\boldsymbol{\mu}=\frac{\boldsymbol{\Delta}_{\boldsymbol{u}}}{\boldsymbol{\Delta}_{\boldsymbol{y}}}$ & $\frac{\boldsymbol{\mu}}{\boldsymbol{\mu}(\boldsymbol{R} \mathbf{c})}$ \\
\hline RC & 1.00 & 6.77 & 42 & 6.2 \\
B35H & 1.26 & 8.56 & 43.7 & 5.1 \\
B75H & 1.04 & 7.07 & 46 & 6.5 \\
\hline
\end{tabular}

Table 8. Energy absorption of beams.

\begin{tabular}{ccc}
\hline Beam & $\begin{array}{c}\boldsymbol{W} \text { (the amount of } \\
\text { energy absorption) }\end{array}$ & $\boldsymbol{W} / \boldsymbol{W}_{\boldsymbol{R} \boldsymbol{C}}$ \\
\hline $\mathrm{RC}$ & 2881.92 & 1.00 \\
$\mathrm{~B} 35 \mathrm{H}$ & 3269.7 & 1.13 \\
$\mathrm{~B} 75 \mathrm{H}$ & 3238.7 & 1.12 \\
\hline
\end{tabular}

provide extra displacement, after which the comparison of ductility values is given in Table 7 . It is shown that the retrofitting of the damaged beam through HPFRCC method improves plasticity of the reference sample approximately by 5 to $25 \%$.

\subsection{Energy absorption of beams}

Energy absorption for each sample is considered as the total area under the load-deflection curve to the failure point of sample or $0.75 P_{u}$, which can indicate the ability of energy dissipation of samples. Table 8 shows the ratio of changes in the energy dissipation caused by the proposed retrofitting. As listed in Table 8, the energy absorption of the retrofitted samples, which are obviously enhanced in comparison to the reference beam, increased.

\subsection{The compression between the samples' theory and experimental bending capacities}

The tension and strain distribution of each point of the RC beam with tensile HPFRCC layer under 
bending force is theoretically considered here. Strain distribution along the height is considered to be linear. The depths of equivalent compressive stress in Vitnee Block $\left(a=\beta_{1} x\right)$ resisting moment of a $\mathrm{RC}$ with a tensile HPFRCC layer $\left(M_{r}\right)$ under bending force are obtained through Eq. (3) based on Eqs. (1) and (2), and $x$ is the value of the neutral axis height.

$$
\begin{aligned}
& \sum F_{x}=0 \Rightarrow 0.85 \cdot f_{c}^{\prime} \cdot a \cdot b+A_{s}^{\prime} \cdot f_{y}-A_{s} \cdot f_{y} \\
& -\sigma_{0 t} \cdot b \cdot t_{H P F R C C}=0, \\
& a=\frac{\left(A_{s}-A_{s}^{\prime}\right) \cdot f_{y}}{0.85 \cdot f_{c}^{\prime} \cdot b}+\frac{\sigma_{0 t} \cdot b \cdot t_{H P F R C C}}{0.85 \cdot f_{c}^{\prime} \cdot b}=\beta_{1} \cdot x, \\
& M_{r}=0.85 \cdot f_{c}^{\prime} \cdot a \cdot b\left(d-\frac{a}{2}\right)+A_{s}^{\prime} \cdot f_{y}\left(d-d^{\prime}\right) \\
& -\sigma_{0 t} \cdot b \cdot t_{H P F R C C} \cdot\left[\frac{t_{H P F R C C}}{2}-(t-d)\right] .
\end{aligned}
$$

According to the above-mentioned equations, providing HPFRCC at the bottom portion of a normal concrete reinforced beam leads to an increase in the depth of equivalent compressive stress $\left(a=\beta_{1} x\right)$, which consequently enhances the resistant anchor of the crosssection. Note that, in this case, the increasing effect of the parameter $\left(a=\beta_{1} x\right)$ is more than the decreasing effect of:

$$
\sigma_{0 t} \cdot b \cdot t_{H P F R C C} \cdot\left[\frac{t_{H P F R C C}}{2}-(t-d)\right] .
$$

Experimental values for bending capacity of damaged beams $M_{\text {exp }}$ and theoretical bending capacity of normal beams $M_{r}$, calculated through Eq. (3), are shown and compared with others in Table 9. The real experimental capacities are almost greater than the theoretical ones. Therefore, the undamaged retrofitted beam capacity is almost $80 \%$ greater than the unretrofitted one $(56.2 / 30.9=1.8)$, although there is a significant increasing capacity due to the HPFRCC layer, thus retrofitting undamaged beams. The experimental results indicate that the higher the percentage of damage, the greater the depth and width of cracks. Thus, the effectiveness of the applied technique should be confirmed by the proposed reduction factor, ranging from 0.7 to 0.85 due to the amount of damage. While the damage is increasing, the $x_{\exp } / x_{r}$ rate is decreasing. It is concluded that if $x_{\exp } / x_{r} \geq 3$, then the beam is $35 \%$ damaged; if $2 \leq x_{\exp } / x_{r} \leq 3$, then the beam is 35 to $75 \%$ damaged; if $x_{\exp } / x_{r}>2$, the beam is at least $75 \%$ damaged.

\section{Conclusion}

Successful application of High-Performance FibreReinforced Cement-based Composite (HPFRCC) materials to structures because of their special stressstrain curve (especially in tension) has put them in the spotlight of interest of researchers. Due to their strain hardening behavior under tension, which are different from other concrete composites, they have become high-performance materials with a significant ability to absorb energy and form many cracks. In this paper, the behavior of HPFRCC material in retrofitting damaged beams was considered experimentally. Results demonstrated that the proposed procedure could be offered as a reliable method for flexural retrofitting of partial damaged reinforced concrete and the main conclusions might be drawn as follows:

- In the reference reinforced concrete beam, cracking of the beam in addition to softening of the stressstrain curve led to a reduction in the bearing capacity of structure and it is worth noting that the reduction rate was directly proportional to the number of cracks. Therefore, in order to ensure the stability of the structure, it is required to take the steel reinforcements into account; however, in the beams retrofitted by HPFRCC at the bottom layer, micro-cracks help the materials enter the softening level, which increases the bearing capacity of the structure;

- In addition, in the reference reinforced concrete beam, yielding of steel reinforcement occurring at the point coincided with the concrete cracks and the destruction caused by mismatch between the concrete and steel, while in the retrofitted beams with HPFRCC, yielding of the steel bars happened along a higher length and a larger area, which would provide the greater capacity of steel reinforcement;

- In all samples, retrofitting increased the initial crack load. Apparently, this phenomenon can justify

Table 9. The compression between theory and experimental bending capacities of the samples retrofitted by High-Performance Fibre-Reinforced Cement-based Composite (HPFRCC) layer.

\begin{tabular}{ccccc}
\hline Beam & Description & $\boldsymbol{M}_{\boldsymbol{r}}$ & $\boldsymbol{M}_{\boldsymbol{e x p}}$ & $\boldsymbol{M}_{\boldsymbol{e x p}} / \boldsymbol{M}_{\boldsymbol{r}}$ \\
\hline RC & Valid beam retrofitted by HPFRCC layer & 56.2 & 56.2 & 1.00 \\
B35H & $35 \%$ damaged beam retrofitted by HPFRCC layer & - & 47.69 & 0.85 \\
B75H & $75 \%$ damaged beam retrofitted by HPFRCC layer & - & 39.55 & 0.70 \\
\hline
\end{tabular}


why the tensile resistance of HPFRCC would be enhanced in the tensile area;

- The maximum increasing rate at the first cracking load of all specimens was $45 \%$. Due to retrofitting, yielding load of tensile reinforcement was incremented by $45 \%$. Final load (destruction load) of samples increased by about $15 \%$ to $40 \%$ in comparison to the reference sample. The slope of the curve of the retrofitted beam was more than that of the reference beam and the reason originated from increase in the intensity of the retrofitted sample in comparison to the reference one;

- By retrofitting the partially damaged beams with HPFRCC method, its ductility attained approximately $90 \%$ of ductility of the reference sample. Comparison of energy absorption of samples indicated that the energy absorption of retrofitted samples increased up to $13 \%$;

- Finally, $35 \%$ and $75 \%$ capacities of the damaged retrofitted beam were found almost 80 and $53 \%$ more than those of un-retrofitted un-damaged ones. Thus, there was a significant increasing capacity due to HPFRCC layer retrofitting. Results demonstrated that the higher the percentage of damage, the lower the effectiveness of the applied technique. Hence, a reduction factor less than unity is suggested due to the amount of damage.

\section{References}

1. Shah, A.A. and Ribakov, Y. "Recent trends in steel fibered high-strength concrete", Material Design, 32, pp. 4122-4151 (2011).

2. Altun, F., Haktanir, T., and Ari, K. "Effects of steel fiber addition on mechanical properties of concrete and RC beams", Construction and Building Material, 21(3), pp. 654-661 (2007).

3. Obaidat, Y.T., Heyden, S., Dahlblom, O., AbuFarsakh, G., and Abdel-Jawad, Y. "Retrofitting of reinforced concrete beams using composite laminates", Construction and Building Material, 25(2), pp. 591597 (2011).

4. Ferreira, D., Bairán, J., and Marí, A. "Numerical simulation of shear-strengthened RC beams", Engineering Structure, 46, pp. 359-374 (2013).

5. Ferrari, V.J., Hanai, J.B., and De Souza, R.A. "Flexural strengthening of reinforcement concrete beams using high performance fiber reinforcement cementbased composite (HPFRCC) and carbon fiber reinforced polymers (CFRP)", Construction and Building Materials, 48, pp. 85-498 (2013).
6. Moatasem, M., Fayyadh, H., and Abdul, R. "Analytical and experimental study on repair effectiveness of CFRP sheets for RC beams", Journal of Civil Engineering and Management, 20(1), pp. 21-31 (2014).

7. Hamdy, M., Afefy, K.N., and Hussein, M. "Enhancement of flexural behavior of CFRP-strengthened reinforced concrete beams using engineered cementitious composites transition layer", Structure and Infrastructure Engineering Journal, 11(8), pp. 1042-1053 (2015).

8. Ahmadpanahi, S.M. "Experimental investigation RC beams using by new technology HPFRCC concretes", Master's Thesis, University of Semnan, Semnan, Iran (2014).

9. Ghasemi Naghibdehi, M., Sharbatdar, M.K., and Mastali, M. "Flexural performance of functionally graded RC cross-section with steel and PP fibres", Magazine of Concrete Research, 6(5), pp. 1-15 (2013). http://dx.doi.org/10.1680/macr.13.00248

10. Hemmati, A., Kheyroddin, A., and Sharbatdar, M.K. "Increasing the flexural capacity of RC beams using partially HPFRCC layers", Computers and Concrete, 16(4), pp. 545-568 (2015).

11. Hemmati, A., Kheyroddin, A., and Sharbatdar, M.K. "Plastic hinge rotation capacity of reinforced HPFRCC beams", ASCE's Journal of Structural Engineering, 141(2), 04014111 (2015). http://dx.doi.org/10.1061/(ASCE)ST.1943-541X.000 0858

12. Hemmati, A., Kheyroddin, A., and Sharbatdar, M.K. "Using HPFRCC for increasing the capacity of R.C. frame", Sharif Journal, Civil Engineering, 3, pp. 97106 (2013).

13. Roumaldi, J.P. and Gordon, B.B., Mechanics of Crack Arrest in Concrete, SP-249-12 (2008).

14. Romualdi, J.P. and James, A.M. "Tensile strength of concrete affected by uniformly distributed and closely spaced short lengths of wire reinforcement", ACI Journal Proceedings, 61(6) (1964).

15. Sheikh, S.H., DeRose, D., and Mardukhi, J. "Retrofitting of concrete structures for shear and flexure with fiber-reinforced polymers", ACI Structural Journal, 99(4), pp. 451-459 (2002).

16. Li, V.C. and Wu, H.C. "Conditions for pseudo strainhardening in fiber reinforced brittle matrix composites", J. Appl. Mech. Rev. 45, pp. 390-398 (1992).

17. Naaman, A.E. and Reinhardt, H.W. "Characterization of high-performance fiber reinforced cement composites", in: Proc. HPFRCC-2, pp. 1-24 (1996).

18. Fischer, G. and Li, V.C. "Structural composites with ECC", in: Proc. ASCCS-6, pp. 1001-1008 (2000).

19. Naaman, A.E., and Reinhardt, H.W. "High performance fiber reinforced cement composites", HPFRCC4, International RILEM Report, Materials and Structures, 36, pp. 710-712 (2004).

20. Li, J. and Zhang, Y.X. "Evolution and calibration of a numerical model for modeling of hybrid-fiber 
ECC panels under high-velocity impact", Composite Structure, 93, pp. 2714-2722 (2011).

21. Jeyasehar, A.C. and Balamuralikrishnan, R. "Strengthening of structures by HPFRCC laminates", Asian Journal of Civil Engineering, 13(1), pp. 29-42 (2012).

22. Suwannakarn, S.W. "Post-cracking characteristics of high-performance fiber reinforced cementitious composites", PhD Thesis, University of Michigan (2009).

23. Wang, S. "Micromechanics based matrix design for engineered cementitious composites", PhD Thesis, University of Michigan (2005).

24. William, K.J. and Warnke, E.P. "Constitutive model for the triaxial behavior of concrete", IABSE Proc., Int. Association for Bridge and Structural Engineering, Zürich, 19 (1975).

25. Kunieda, M. and Rokugo, K. "Measurement of crack opening behavior within ECC under bending moment", in International RILEM Workshop HPFRCC in Structural Applications, pp. 313-322 (2006).

\section{Biographies}

Mohammad Kazem Sharbatdar obtained his MS degree from Amirkabir University, Tehran, Iran and his PhD degree from Ottawa University in Canada. He is currently an Associate Professor in the Faculty of Civil Engineering at Semnan University, Iran. He has authored 5 books, more than 25 ISI and ISC journal papers, and more than 130 conference papers. He has 5 patents. He has also supervised numerous MS and $\mathrm{PhD}$ degree theses.

Javad Ayyubi obtained an MS degree in Structural Engineering from Semnan University, Iran with his thesis on strengthening of damaged reinforced concrete beams using HPFRCC new material. He is a university instructor of Civil Engineering right now. His interest is in studying and researching the application of HPFRCC to different deficient reinforced concrete members and he is now concentrated more on finite element. 